\title{
Trajetórias de professores de Sociologia e as dinâmicas da comunidade disciplinar no estado do Rio de Janeiro
}

\author{
Paths of Sociology teachers and the dynamics of the disciplinary \\ community in the state of Rio de Janeiro
}

\author{
Trayectorias de docentes de Sociología y dinámica de la \\ comunidad disciplinaria en el estado de Río de Janeiro
}

Gustavo Dias da Silva'

https://orcid.org/0000-000I-8430-1545

Mariana Lima Vilela ${ }^{2}$

https://orcid.org/00000003-024|-286|

\begin{abstract}
Resumo: A pesquisa focaliza a comunidade disciplinar de Sociologia e trajetórias de professoras do Ensino Médio no Rio de Janeiro. Assenta-se sobre os conceitos de comunidade disciplinar e construção social do currículo (BALL, MAGUIRE e BRAUN, 2016; HOBSBAWN e RANGER, 1997; GOODSON, 1997; 2001; 2012). Por meio de entrevistas semiestruturadas, relaciona histórias dos grupos disciplinares com a trajetória profissional de três entrevistadas, focalizando: (i) disputa por recursos, status e territórios; (ii) invenção de tradições; e (iii) retórica em defesa da disciplina. Os resultados apontam a mobilização de discursos da comunidade disciplinar em políticas educacionais, fortalecendo argumentos em favor da disciplina na escola básica. A promulgação da Lei I I.684/2008 marca a luta pela consolidação da carga horária semanal da disciplina. Indica-se um crescente fortalecimento da comunidade disciplinar e conquistas nas políticas educacionais, por meio da construção de redes que subsidiam práticas dos docentes de Sociologia.
\end{abstract}

Palavras-chave: História das disciplinas escolares. Disciplina escolar Sociologia. Comunidade disciplinar.

Abstract: The research focuses on the disciplinary community of Sociology and professional paths of high school teachers in Rio de Janeiro. It is based on the concepts of disciplinary community and social construction of the curriculum (BALL, MAGUIRE and BRAUN, 2016; HOBSBAWN and RANGER, 1997; GOODSON, 1997; 200I; 2012). Through semi-structured interviews, it relates stories of the disciplinary groups with the professional path of three interviewees, focusing on: (i) dispute over resources, status and territories; (ii) invention of traditions;

\footnotetext{
I Mestre em Educação pela UFF - Universidade Federal Fluminense. Técnico Assistente do IFF - Instituto Federal Fluminense. E-mail: silvagustavodias@gmail.com

2 Doutora em Educação pela UFF - Universidade Federal Fluminense. Docente da Faculdade de Educação da UFF Universidade Federal Fluminense. E-mail: m.limavilela@gmail.com
} 
and (iii) rhetoric in defense of the school subject. The results point to the mobilization of discourses of the disciplinary community in educational policies, strengthening arguments in favor of Sociology as a school subject. The enactment of Law II,684 / 2008 marks the ongoing struggle to consolidate the school subject's weekly workload. A growing strengthening of the disciplinary community and achievements in educational policies are indicated, through the construction of networks that subsidize the practices of Sociology teachers.

Keywords: History of school subjects. School subject Sociology. Disciplinary Community.

Resumen: La investigación se centra en la comunidad disciplinaria de Sociología y las trayectorias de los maestros de secundaria en Río de Janeiro. Se basa en los conceptos de comunidad disciplinaria y construcción social del curriculo (BALL, MAGUIRE y BRAUN, 2016; HOBSBAWN y RANGER, 1997; GOODSON, 1997; 200I; 20I2). A través de entrevistas semiestructuradas, relata historias de grupos disciplinarios con la trayectoria profesional de tres entrevistados, enfocándose en: (i) disputas sobre recursos, estatus y territorios; (ii) invención de tradiciones; y (iii) retórica en defensa de la disciplina. Los resultados apuntan a la movilización de discursos de la comunidad disciplinaria en las políticas educativas, fortaleciendo los argumentos a favor de la disciplina en la escuela básica. La promulgación de la Ley II.684 / 2008 marca la lucha continua para consolidar la carga de trabajo semanal de la disciplina. Se indica un creciente fortalecimiento de la comunidad disciplinaria y los logros en las políticas educativas, a través de la construcción de redes que subsidian las prácticas de los maestros de sociología.

Palabras-clave: Historia de las asignaturas escolares. Asignatura escolar Sociología. Comunidad disciplinaria.

\section{Introdução}

As disciplinas escolares são definidas, existem ou não, em função de disputas por projetos para Educação que interagem em diferentes esferas das políticas curriculares. A partir dessa perspectiva, Goodson (2012) compreende as histórias das disciplinas escolares e do próprio processo de escolarização. Assim também compreendemos a Sociologia como disciplina escolar, objeto de estudo da presente pesquisa, cujo objetivo é investigar trajetórias de professores de Sociologia e seu papel na construção social do currículo desta disciplina.

Cabe ressaltar que o estudo ocorre em um momento singular das políticas curriculares para a disciplina escolar Sociologia. Em 2016, o governo Temer editou por meio de Medida Provisória a Reforma do Ensino Médio, a qual se transformaria, posteriormente, na Lei 13.415/2017 (BRASIL, 2017). Nesta recente regulamentação, o inciso IV, do artigo 36, da Lei de Diretrizes e Bases (LDB), o qual garantia a inclusão de Sociologia e da Filosofia como disciplinas obrigatórias no Ensino Médio, é substituído pela obrigatoriedade de "ciências humanas e sociais aplicadas". Essa perda da garantia legal das disciplinas no currículo é ainda reforçada pela posterior aprovação da Base Nacional Comum Curricular (BNCC), bem como em alterações na política de formação de professores, tomadas sem um debate mais amplo com a sociedade.

Goodson (200I) destaca que os movimentos de reforma curriculares intensificam as disputas em torno do currículo e da sua construção social (GOODSON, 200I). Hobsbawn e Ranger (1997) afirmam que os momentos de transformações rápidas e momentâneas são propícios para a invenção de tradições, em outras palavras, estabilização de práticas através de um desejo de construir uma

Olhar de Professor, Ponta Grossa, v. 24, p. I-22, e-I4954.00I, 202 I.

Disponível em https://revistas2.uepg.br/index.php/olhardeprofessor 
ligação com um passado. Além disso, Lopes (2005) elucida através do conceito de hiperpolitização, que sentidos em aberto aparecem, na verdade, mobilizados numa disputa constante por seus significados num processo de recontextualização e hibridismo. Ou seja, de acordo com esse conjunto de autores, os movimentos de reforma representam uma época intensa de lutas em torno das políticas curriculares.

Por um outro ângulo de análise, e de forma complementar, a perspectiva de Ball, Maguire e Braun (2016) valoriza os contextos de produção curricular em espaços de micropolíticas, buscando compreender como as variáveis dinâmicas dos contextos de atuação docente dão formas à atuação política e, portanto, à própria materialidade dos currículos. Essa perspectiva também busca valorizar as culturas profissionais de professores em ação oferecendo subsídios à interpretação sobre como os professores atribuem sentidos em sua prática respondendo de forma ativa e criativa às demandas externas de supostas implementações de currículos. Nesse sentido, a compreensão da Sociologia como disciplina escolar passa também pelo seu entendimento histórico, pela análise das estruturas do processo histórico de luta dos sujeitos do contexto da prática pela sua permanência no currículo da Educação Básica.

Com base nessa compreensão das dinâmicas curriculares, esta pesquisa rejeita o papel de sujeito passivo dos professores diante das políticas públicas em educação. E, por conseguinte, busca compreender a potência das histórias singulares da atuação professores de Sociologia ao articular de modo dialético parte de suas trajetórias profissionais com quadros políticos mais amplos. O presente artigo apresenta parte dos resultados de uma pesquisa de mestrado em Educação que teve como objetivo investigar relações entre as trajetórias de professoras do Ensino Médio e a construção social da disciplina Sociologia no Estado do Rio de Janeiro.

\section{Particularidades da comunidade disciplinar de Sociologia no estado do Rio de Janeiro}

O início do debate sobre a inserção da disciplina Sociologia na Educação básica remonta ao início do século XIX (MORAES, 20I I). Um primeiro impulso contundente de sua institucionalização no currículo ocorre entre meados da década de 1920 e 1940, até a sua efetiva exclusão na Reforma Capanema em 1942. Essa intermitência da disciplina e o recorrente movimento pelo seu retorno no currículo da Educação Básica no Brasil podem ser considerados uma marca histórica (MORAES, 20I I; OLIVEIRA, 20I3; SANTOS, 2004).

Durante a década de 1980, acompanhando o movimento para redemocratização do país, ocorre um novo impulso para a inserção da Sociologia nas escolas de ensino secundário. No entanto, diferente da relevância da Sociologia das primeiras décadas do século $X X$, com os propósitos de

Olhar de Professor, Ponta Grossa, v. 24, p. I-22, e-I4954.00I, 202 I.

Disponível em https://revistas2.uepg.br/index.php/olhardeprofessor 
construção da nação, nos anos de 1980 passa-se a valorizar um novo significado: a formação para a cidadania (OLIVEIRA, 20I3). A partir desse significado é construída uma retórica de defesa da disciplina bastante forte e presente no ensino de Sociologia até os dias atuais (MAIÇARA; MONTEZ; GESTEIRA, 2015; MOTA, 2005). Nesse movimento, estados como o Rio de Janeiro, Rio Grande do Sul, Pernambuco, Pará, Distrito Federal e São Paulo inserem no decorrer da década de 80 a disciplina Sociologia em seus currículos (SANTOS, 2004).

A partir de 1994, porém, alguns estados como São Paulo cedem espaços de carga horária da disciplina para outras mais tradicionais, como Português e Matemática, diante da política de reestruturação da Rede Pública. Essa trajetória intermitente seria um efeito, sobretudo do ambíguo artigo 36 da Lei de Diretrizes e Bases (LDB) de 1996, o qual possibilitava a interpretação da obrigatoriedade apenas dos conhecimentos sociológicos. A lei apontava para uma concepção transdisciplinar, negando (ou dificultando) a afirmação de uma disciplina (OLIVEIRA, 20I3).

Não obstante, percebemos uma "virada" pela obrigatoriedade, a partir de 1997, com a movimentação mais incisiva de profissionais em defesa da sua obrigatoriedade nacional (HANDFAS; MAIÇARA, 20I5). Nesse momento, associações profissionais movimentam-se nacionalmente em defesa da disciplina no Ensino Médio, realizando encontros e congressos sobre o tema. $O$ debate pela obrigatoriedade entra na pauta do Conselho Nacional de Educação (CNE) e o Parecer n. 38/2006 é aprovado sem ressalvas, tornando obrigatória a disciplina em todo o país. Em 2008, para resolver questionamento de entidades do Estado de São Paulo sobre a autonomia do CNE para alterar o currículo nacional, após dois anos de tramitação no Congresso e no Senado, é sancionada a Lei II.684 que altera o artigo $36 \mathrm{da}$ LDB, tornando obrigatória a presença de Sociologia e Filosofia em todos os anos do Ensino Médio. A partir de então a disciplina passa a figurar entre as principais políticas nacionais para a educação, com destaque para o seu ingresso no Programa Nacional do Livro Didático (PNLD), em 20 I2, bem como para a emergência de questões que envolvam os conceitos da Sociologia no Exame Nacional do Ensino Médio (ENEM). No Estado do Rio de Janeiro salientamos as políticas de elaboração de um Currículo Mínimo para o Ensino Médio em 2010 e $201 \mathrm{I}$.

O caso do Rio de Janeiro se distingue de uma certa maneira da narrativa nacional, já que a disciplina aparece como obrigatória desde a promulgação da Constituição do Estado em I989. E além disso, é possível observar uma comunidade de profissionais organizada na defesa da disciplina no Estado que procura se articular a movimentos sociais contemporâneos e outros atores participantes do processo educacional. Na década de 1980, aliada aos impulsos de redemocratização, e de movimentos sociais, a Associação Profissional dos Sociólogos do Estado do Rio de Janeiro (APSERJ) passa a atuar em prol da regulamentação da profissão. A Lei que dispõe sobre o exercício da profissão de Sociólogo 
é promulgada em dezembro de 1980 e atribui a este profissional a competência de ensinar Sociologia geral ou especial nos estabelecimentos de ensino (BRASIL, 1980).

A partir de uma flexibilização curricular induzida pela Lei 7.044 de 1982, os Estados ganharam mais autonomia na elaboração do currículo escolar. E o Estado do Rio de Janeiro contou com uma associação profissional estadual na vanguarda desse processo (SOUZA, HANDFAS; FRANÇA, 20I2). Houve uma forte articulação com movimentos sociais pela redemocratização, com movimentos estudantis, professores universitários e membros dos poderes legislativo e executivo em nível estadual na época.

Em 1989, a APSERJ inicia uma campanha intitulada “Pela volta da Sociologia no $2^{\circ}$ Grau”. Esta ação é encampada pelo Deputado Estadual Accácio Caldeira, do Partido Democrático Trabalhista (PDT). E assim, temos a inclusão da Sociologia no Ensino Médio do Rio de Janeiro aprovado na Constituinte Estadual em 1989. No entanto, o parágrafo $4^{\circ}$ do artigo 317 versa apenas sobre a obrigatoriedade da presença da disciplina, sem especificar carga horária. A partir deste momento, a associação concentrou seus esforços para garantir o seu cumprimento (SOUZA, HANDFAS; FRANÇA, 20I2).

Entre os anos de 1996 e 2004, as lutas políticas em torno da Sociologia no Ensino Médio no âmbito estadual se arrefeceram. Souza (2008) aponta uma comunidade difusa, com ações pontuais nas universidades, entre professores do ensino básico e entre alguns sociólogos. Conterato (2009) identifica uma lacuna entre meados da década de 90 e a obrigatoriedade nacional, em 2008. Souza, Handfas e França (20I2), focalizando o Estado do Rio de Janeiro, explicitam que, em meados da década de 90, "concursos públicos foram realizados, corrigindo assim uma distorção corrente da existência de professores formados em outras áreas disciplinares" (SOUZA, HANDFAS; FRANÇA, 20I2). Este hiato coincide com a "virada" para obrigatoriedade nacional, o que nos leva a crer que a mobilização da defesa da Sociologia no Estado do Rio de Janeiro se voltou para uma questão mais nacional entre os períodos de 1996 e 2004.

\section{Comunidade disciplinar, retóricas e tradições: disciplinas escolares como construção social}

O conceito de comunidade disciplinar proposto por Goodson (1997) contribui para compreender a ação de indivíduos ou grupos sociais e seu papel na construção social das disciplinas escolares. Segundo o autor:

A comunidade disciplinar não deveria ser vista como um grupo homogêneo cujos membros comungam dos mesmos valores e definição de papéis, interesses e

Olhar de Professor, Ponta Grossa, v. 24, p. I-22, e-14954.00I, 2021.

Disponível em https://revistas2.uepg.br/index.php/olhardeprofessor 
identidades. A comunidade disciplinar deve ser vista, sim, como um movimento social incluindo uma gama variável de missões ou tradições distintas representadas por indivíduos, grupos, segmentos ou facções. A importância destas facções varia consideravelmente ao longo do tempo. (GOODSON, 1997, p. 44)

Para o autor, as comunidades disciplinares constroem retóricas apropriadas para promover a estabilidade e permanência de uma disciplina no currículo. Uma comunidade disciplinar fortalecida constrói retóricas e categorias as quais integram interesses materiais, morais e idealistas de forma a parecer naturalizada na política curricular (GOODSON, 1997). Assim, cristalizam-se as práticas e sua presença no currículo oficial passa a ser praticamente inquestionável.

De outra perspectiva, Costa e Lopes (2016) revisitam este conceito de Goodson a partir de perspectivas pós-estruturalistas. Os autores consideram a comunidade disciplinar como um conceito potente para pensar as disputas curriculares. No entanto, para eles, a comunidade disciplinar não tem lugares pré-definidos, e nem a partir de indivíduos, grupos ou facções pré-estabelecidos. Também não se resume a um movimento social, pois suas fronteiras mostram-se constantemente negociadas, na tentativa do próprio fortalecimento da sua legitimação. Assim, os autores entendem comunidade disciplinar como um discurso:

A comunidade disciplinar, pela argumentação que construímos, é o conjunto de subjetividades constituídas em operações provisórias no campo discursivo da disciplina. A comunidade e as subjetividades/identificações não possuem uma origem, uma gênese. Seus saberes são construídos ao passo em que as subjetivações disciplinares também o são. É por meio de diferentes lutas políticas que campos disciplinares são organizados, organizando simultaneamente as identificações disciplinares (COSTA; LOPES, 2016, p. 1028).

Esta abordagem de comunidade disciplinar se aproxima mais daquilo que Ball (1993) chamou de política como discurso. $O$ enfoque consiste em "entender as articulações que constituem discursos disciplinares e assim subjetivam os coletivos que falam em nome da disciplina, que dela se utilizam como oportunidade de envolvimento na política" (COSTA; LOPES, 2016, p. 1028).

Estas duas perspectivas não são necessariamente contraditórias. Ainda que haja diferenças. $A$ distinção que Ball (1993) faz entre política como texto e política como discurso desenha as possiblidades e os limites destas abordagens. Estes dois olhares são potentes e complementares. Se por um lado interpretarmos a comunidade disciplinar nos termos de Goodson (1997), podemos surpreender os professores jogando o jogo da estabilização disciplinar; mobilizando categorias em prol da construção de uma retórica para defesa da disciplina. Por outro, ao considerarmos a perspectiva pós-estruturalista de Costa e Lopes (2016), observaremos um discurso de comunidade disciplinar a partir de demandas disciplinares e/ou curriculares, as quais conformam e são formadas pelo contexto da prática dos professores.

Olhar de Professor, Ponta Grossa, v. 24, p. I-22, e-I4954.00I, 202 I.

Disponível em https://revistas2.uepg.br/index.php/olhardeprofessor 
Nossa concepção de comunidade disciplinar, portanto, transita entre essas duas perspectivas. Pois, para além de questões ontológicas, ambas nos fazem entender que a prática dos professores se mostra articulada com uma rede de relações maiores do que ela em si. Seja a retórica que defende a disciplina, seja um discurso que legitima e silencia práticas e saberes, estas categorias aparecem em movimento. A existência de uma comunidade disciplinar é inseparável à sua trama, às suas disputas, às suas lutas.

Além disso, para Ball (1993) um discurso bem-sucedido é capaz de ocultar sua própria invenção. Uma das formas de ocultá-la é atribuir o sentido de tradição às invenções. Goodson (1997) aproveita o termo "tradição inventada" cunhado por Hobsbawn e Ranger (1997), para descrever o processo pelo qual o currículo acaba parecendo uma prática naturalizada. Para Hobsbawn e Ranger (1997), a "tradição inventada" intenta uma relação contínua com um passado. Com efeito, os grupos disciplinares desenvolvem práticas que buscam coesão social, ou que procuram definir valores, sentidos e significados. Assim, os autores ressaltam que uma tradição inventada se conecta muito mais com o passado do que com um pragmatismo, ou com argumentos racionais. Em diálogo com essas ideias, Goodson (1997) argumenta que o currículo escolar é uma invenção de tradição.

Neste ponto reside a principal distinção entre dois conceitos relacionados às ações das comunidades disciplinares que mobilizamos na presente pesquisa: retórica e tradição inventada. Enquanto a primeira se relaciona diretamente com o tempo presente, negociando moral, ideal e materialmente com as condições socioculturais vigentes; a segunda se liga com o tempo pretérito, ou busca nas tradições do currículo elementos que fundamentem sua existência. Sua base consiste no empenho pela aceitação automática, pela repetição dos valores, comportamentos e ideias. Estes dois conceitos - retórica em defesa da disciplina e tradição inventada - se apresentam como o significado da dinâmica de um grupo disciplinar e são dois movimentos complementares na defesa de uma disciplina escolar, e na construção social do currículo.

\section{Estratégias metodológicas de integração entre a história da disciplina Sociologia e as trajetórias docentes}

A produção de dados empíricos da pesquisa envolveu entrevista semiestruturada com professoras de Sociologia de escolas do Estado do Rio de Janeiro. Nossa opção metodológica se baseia em Gill e Goodson (2015) com enfoque qualitativo e biográfico para a coleta de dados mediante entrevistas aprofundadas. Por meio de entrevistas semiestruturadas (DUARTE, 2004) desenvolvem-se diálogos e intercâmbios que transformam a entrevista em uma conversa fundamentada e assim, afastase a narrativa de um mero relato singular, buscando a triangulação das informações narradas com

Olhar de Professor, Ponta Grossa, v. 24, p. I-22, e-I4954.00I, 2021.

Disponivel em https://revistas2.uepg.br/index.php/olhardeprofessor 
outras fontes. Isso permite situar o relato em um significado mais amplo (GILL e GOODSON, 2015. p 218).

Assim, a partir dos dados das entrevistas, tentamos construir narrativas que procuram desenhar a trajetória profissional das professoras em relação à história da disciplina escolar. Para selecionar os entrevistados elaboramos e divulgamos para professores de universidades do Rio de Janeiro, ligados à Licenciatura em Ciências Sociais, um questionário on line para a obtenção de contatos de professores de Sociologia do Ensino Médio dispostos a conceder entrevistas. O questionário foi destinado a professores de Sociologia da Educação Básica, sem restringir a formação específica em Ciências Sociais ou a atuação exclusiva na rede Estadual de ensino. Ao todo, obtivemos 12 (doze) respostas.

Para selecionar os respondentes adotamos como critérios de seleção a localidade onde o professor atua e o período de início no magistério. Com a intenção de observar contextos distintos, selecionamos professores que trabalharam em diferentes cidades ou regiões. E além disso, selecionamos professores que iniciaram suas carreiras na década de 90, anos 2000, e após a obrigatoriedade da Sociologia, em 2008, com o intuito de perceber os diferentes contextos históricos da disciplina e as suas relações com a biografia das entrevistadas.

Diante destes critérios, foram selecionadas três professoras: A professora A - cuja carreira começou na década de 90, e trabalha na região metropolitana do Rio; A professora B - que iniciou o magistério na baixada litorânea em meados dos anos 2000; E a professora C - que trabalha no município de Niterói (RJ), tendo assumindo o cargo em 2009.

De fato, o tamanho da amostra e o recorte provocado pelas escolhas metodológicas, criam um limite para qualquer tipo de generalização. Não é a pretensão deste trabalho produzir uma história definitiva, ou narrativas totalizantes que expliquem todos percursos possíveis da sociologia escolar. Nosso enfoque consiste em contribuir para "desenvolver um entendimento cumulativo dos contextos históricos nos quais está inserido o currículo contemporâneo" (GOODSON, 20I2, p.68). Por isso, a compreensão dos contextos históricos em que se desenvolvem as histórias de vida aparece mais valorizada do que o número de entrevistas. Existem e sempre existirão muitas narrativas a serem descobertas. Entendemos que as histórias das três professoras selecionadas contribuem com o "entendimento cumulativo" dos contextos onde a sociologia escolar é desenvolvida, sem aspirar encerrar todas as realidades possíveis.

Para que a entrevista tivesse um efeito de conversa fundamentada (GILL e GOODSON, 20I5), foi elaborado um roteiro de entrevista semiestruturada, em diálogo com os referenciais teóricos discutidos, abordando três temas centrais: a) profissão professor de sociologia e o seu papel no 
contexto escolar; b) construção social do currículo de sociologia escolar; c) tessitura da comunidade disciplinar de sociologia. No quadro a seguir, apresentamos a organização destes temas com seus tópicos e seus objetivos que serviram como guia das entrevistas semiestruturadas.

Quadro I - Roteiro de entrevista semiestruturada

\begin{tabular}{|c|c|c|}
\hline Tema & Tópicos & Objetivos \\
\hline \multirow[b]{2}{*}{$\begin{array}{l}\text { Profissão professor } \\
\text { de sociologia }\end{array}$} & Apresentação Inicial & $\begin{array}{l}\text { I - Caracterizar a trajetória do professor na } \\
\text { profissão; } \\
2 \text { - Buscar as diferentes “entradas” na profissão } \\
\text { conforme o tempo; }\end{array}$ \\
\hline & Sobre a carreira & $\begin{array}{l}\text { I - Identificar diferentes atuações dos professores } \\
\text { de Sociologia; } \\
2 \text { - Relacionar a atuação fora da sala de aula com a } \\
\text { estabilização da disciplina no currículo; } \\
3 \text { - Identificar os sentidos que são atribuídos à } \\
\text { presença do professor de sociologia na escola. }\end{array}$ \\
\hline \multirow{2}{*}{$\begin{array}{l}\text { Construção social do } \\
\text { currículo de } \\
\text { sociologia escolar }\end{array}$} & $\begin{array}{l}\text { Relação com o } \\
\text { currículo mínimo de } \\
\text { Sociologia }\end{array}$ & $\begin{array}{l}\text { I - Identificar os temas mais relevantes da } \\
\text { sociologia escolar para os professores; } \\
2 \text { - Perceber a transição da sociologia acadêmica } \\
\text { para a sociologia escolar; } \\
3 \text { - Caracterizar o estágio da sociologia conforme } \\
\text { Goodson (Utilitário, Pedagógico, Acadêmico). }\end{array}$ \\
\hline & $\begin{array}{l}\text { O lugar da sociologia } \\
\text { na escola básica. }\end{array}$ & $\begin{array}{l}\text { I - Relacionar os principais temas com o papel da } \\
\text { sociologia na escola básica; } \\
2 \text { - Perceber o lugar da sociologia na escola básica } \\
\text { e na comunidade escolar. }\end{array}$ \\
\hline \multirow{2}{*}{$\begin{array}{l}\text { Tessitura da } \\
\text { comunidade } \\
\text { disciplinar de } \\
\text { sociologia }\end{array}$} & $\begin{array}{l}\text { Os professores na }(\mathrm{da}) \\
\text { comunidade disciplinar } \\
\text { de Sociologia }\end{array}$ & $\begin{array}{l}\text { I - Compreender as relações tecidas no interior } \\
\text { da comunidade disciplinar de sociologia. }\end{array}$ \\
\hline & $\begin{array}{l}\text { A defesa da disciplina } \\
\text { sociologia }\end{array}$ & $\begin{array}{l}\text { I - Identificar os argumentos de defesa da } \\
\text { disciplina de sociologia na perspectiva dos } \\
\text { professores; } \\
2 \text { - Caracterizar os discursos circulantes a partir } \\
\text { dos professores de sociologia; }\end{array}$ \\
\hline
\end{tabular}

Fonte: produzido pelos autores, 2019.

As entrevistas foram gravadas em áudio e transcritas e as análises buscaram orientar-se pela ideia de triangulação proposta por Gill e Goodson (20I5):

O objetivo da análise é mostrar como as pessoas compreendem sua experiência vivida e como a narração dessa experiência lhes dá condições para interpretar o mundo social e sua atuação dentre dele. Geralmente não se trata de revelar a verdade dos relatos. $O$ enfoque da análise é determinado pelas questões de pesquisa, a postura epistemológica do pesquisador e sua experiência vivida com relação ao tema da pesquisa (GILL; GOODSON, 2015, p. 219).

A partir das transcrições foram realizadas análises procurando desenhar a trajetória profissional das professoras em relação à história da disciplina escolar Sociologia.

Olhar de Professor, Ponta Grossa, v. 24, p. I-22, e-I4954.00I, 202 I.

Disponível em https://revistas2.uepg.br/index.php/olhardeprofessor 
Trajetórias de professores de Sociologia e as dinâmicas da comunidade disciplinar no estado do Rio de Janeiro

\section{Comunidade disciplinar em movimento: encontros entre trajetórias docentes e história da disciplina Sociologia no estado do Rio de Janeiro}

As narrativas obtidas por meio de entrevistas expressam a comunidade disciplinar em movimento, e corroboram com Oliveira e Cigales (2019), constituindo uma rede de relações recíprocas com trajetória de vida de cada professora entrevistada. As histórias contadas pelas professoras nos fazem percorrer outras histórias, outros espaços, e outros sujeitos, alargando a fronteira da narrativa da comunidade disciplinar. Para descrever estes processos, organizamos a apresentação dos resultados em três categorias: I) disputas por recursos, território e status; 2) invenções de tradições; 3 ) construção da retórica da defesa da disciplina.

I. Disputas por recursos, território e status: a conquista de dois tempos semanais

$\mathrm{Na}$ década de 90, época de ingresso da professora A na carreira, a Sociologia era ministrada com dois tempos semanais de aula no terceiro ano. Do ano de entrada da professora até o ano letivo de 2010, não houve alterações na carga horária destinada à disciplina. Conforme já observamos, após a luta pela inserção da disciplina na constituinte do Estado do Rio de Janeiro, os esforços dos defensores da Sociologia se concentraram em garantir que os cientistas sociais ocupassem o lugar dos professores da disciplina na escola básica (SOUZA; HANDFAS; FRANÇA, 20I2). Por isso, a entrada da professora A na escola poderia até se mostrar conflituosa pelo fato de uma professora de outra área já ocupar o lugar do professor de Sociologia. Entretanto, não houve conflito haja vista o respeito à resolução que concedia primazia ao professor concursado para a área. $\mathrm{Na}$ narrativa da nossa entrevistada, portanto, a disciplina aparece com uma situação estável a época.

Do mesmo modo, a professora B, cuja entrada no magistério estadual ocorreu em 2005, três anos antes da Lei da obrigatoriedade, demonstra a estabilidade da disciplina no momento inicial da sua carreira. Mesmo que a condição estável da Sociologia de dois tempos semanais no terceiro ano do Ensino Médio fosse verificada na narrativa das professoras, isto não significa a inexistência de questionamentos em torno da disciplina.

Os relatos da professora A nos mostram como a questão da continuidade e a ausência da disciplina em outras etapas da escolarização básica afetaram sua carreira, na medida em que os próprios colegas professores e estudantes questionam o porquê da Sociologia na escola. E questões do sentido e do papel do professor de Sociologia na escola acompanham os anos iniciais da professora B. Mesmo que não houvesse nenhum posicionamento oficial, ou que fossem apenas comentários "sutis" de colegas, o questionamento da disciplina marcou este momento inicial da carreira das professoras. A presença da disciplina na grade curricular nesta época nunca deixou de ser questionada segundo as

Olhar de Professor, Ponta Grossa, v. 24, p. I-22, e-I4954.00I, 2021.

Disponível em https://revistas2.uepg.br/index.php/olhardeprofessor 
narrativas das professoras. Portanto, é preciso compreender que esta estabilidade, dos anos anteriores à obrigatoriedade, apresentada pelas professoras se distancia do que Goodson entende como disciplina de padrão estável, ou seja, que aparece naturalizada no processo de escolarização (GOODSON, 1997), caracterizando uma estabilidade frágil e com pouca legitimidade.

As poucas alterações na carga horária da Sociologia no Estado antes da lei da obrigatoriedade, e a invisibilidade do discurso pela ampliação do seu espaço curricular também sugerem que às professoras entrevistadas, neste período, participavam da comunidade disciplinar de Sociologia de um modo restrito ao contexto da prática. Neste sentido, a luta por território, recursos e status não transcendiam para outras esferas das políticas educacionais.

Após a promulgação da obrigatoriedade, em 2008, e da Resolução $n^{\circ}$ I/2009 do Conselho Nacional de Educação (CNE), dispondo sobre a implementação e estipulando prazo para a inserção da Sociologia e da Filosofia nas matrizes curriculares, a SEEDUC/RJ edita um documento que altera a grade curricular do Ensino Médio no Estado. De acordo com a Resolução nº. 4359/2009 (SECRETARIA DE ESTADO DE EDUCAÇÃO, 2009), a Sociologia teria, a partir do ano letivo de 2010, um tempo de aula de 50 (cinquenta) minutos no primeiro e no segundo ano semanalmente, e continuaria com os dois tempos semanais no terceiro ano. Estas mudanças mostraram-se drásticas para a carreira das professoras entrevistadas. A professora A observou na sua escola a chegada de mais profissionais em conjunto com o aumento da carga horária. E é neste período, que a professora $\mathbf{C}$ ingressa no magistério.

Assim, este período de ingresso de professores, de ampliação da carga horária da disciplina na grade curricular representa a intensificação de processos de disputas em torno do currículo. Por conseguinte, percebemos um fortalecimento da comunidade disciplinar, no desenvolvimento do movimento social e do discurso em defesa da disciplina. Novos professores são recrutados, e, no caso específico da Sociologia, obteve-se mais espaço no horário escolar. E os ganhos de tempo na grade curricular não se restringiram à conquista de território nas narrativas. Conforme os relatos da professora B, a Sociologia atingiu um patamar tal qual a de disciplinas mais consagradas como História e Geografia, para se integrar no quadro das Ciências Humanas. Neste sentido, o aumento da carga horária significou também conquista de status.

Não obstante este ganho para a defesa da disciplina no Ensino Médio, as três entrevistadas sinalizam para o fato deste período pós-obrigatoriedade coincidir com uma precarização nas condições de trabalho, sobretudo com aumento de turmas por professor. E também superlotação de estudantes nas turmas; exigências de se cumprir com o conteúdo sem o tempo necessário. Estes são alguns exemplos de precarização do trabalho docente que conseguimos capturar nas narrativas. A 
professora B lembra desse período sempre se referindo à quantidade de licenças médicas que ela precisou. Foram "anos árduos", nas palavras da professora A.

As narrativas suscitam as ambiguidades no processo pós-obrigatoriedade. Se por um lado a comunidade disciplinar se fortalece na conquista de status território e recursos, por outro lado, as condições de trabalho docente são precarizadas, e instituem-se formas gerenciais de estado para o controle dos professores.

Evidentemente o conjunto das políticas educacionais provocadas pelo o Estado não atingiu apenas os professores de Sociologia. Ao analisarmos a movimentação do Sindicato Estadual dos Profissionais da Educação (SEPE/RJ), percebemos um momento de bastante agitação. Entre 2010 e 2016, temos quatro greves - em 20II, 20I3, 2014 e 2016 -, além de diversos "estados de greve", paralisações e greves de advertência. Estes períodos de disputas em resposta à "fase árdua" das nossas entrevistadas, pode ter gestado uma demanda disciplinar (COSTA; LOPES, 20I6): nenhuma disciplina com menos de dois tempos semanais. Esta demanda apareceu, inicialmente, nas pautas dos professores do Estado em 2012, e se organizou a partir da construção de um grupo específico dentro do Sindicato Estadual dos Profissionais da Educação do Rio de Janeiro (SEPE/RJ) para tratar da luta pelos dois tempos semanais. Os professores de Sociologia e de Filosofia representavam os principais mobilizadores deste debate.

É neste sentido, que conseguimos observar os professores de Sociologia se fortalecendo como comunidade disciplinar, como um movimento social, a partir da apropriação de espaços para a luta de uma demanda específica da disciplina. Cabe ressaltar, que este fortalecimento ocorre na medida em que se estreitam redes com os professores de Filosofia.

A entrevista da professora $\mathbf{A}$ indica ainda um amadurecimento deste laço entre Filosofia e Sociologia, quando ela relata sua participação no Fórum de Professores de Filosofia e Sociologia. Parece-nos importante notar o surgimento destes espaços, na medida em que eles, nas palavras da professora, "contribuem para romper com o isolamento dos professores". O Fórum de Professores de Filosofia e Sociologia nasce em 2012, no interior dos debates do Sindicato Estadual dos Profissionais de Educação do Estado do Rio de Janeiro (SEPE/RJ), até tornar-se uma demanda específica, e, por assim dizer, um movimento social característico destas disciplinas.

Em 2016, o pleito pelos dois tempos semanais transcende os movimentos dos professores do Estado e surge nas reinvindicações das ocupações dos estudantes nas escolas estaduais no Rio de Janeiro. A mobilização estudantil de ocupação de escolas apresenta como demanda que nenhuma disciplina tenha menos que dois tempos (QUEIROZ; BORTOLON; ROCHA, 20I7). As ocupações, sem dúvidas, trazem e despertam diversos sentidos nas narrativas das professoras. 
A circulação desta demanda curricular pode ser compreendida como um sinal de amadurecimento da comunidade disciplinar de Sociologia no Estado do Rio de Janeiro, na medida em que novos atores aparecem na disputa curricular se apropriando do pleito apontado pelas nossas entrevistadas como fundamental para a melhoria das condições de trabalho dos docentes.

As ocupações, portanto, aparecem como um fortalecimento da comunidade disciplinar como discurso, nos termos de Costa e Lopes (2016). Um discurso cujo aparecimento fortaleceu (e até mesmo recriou) as identidades como professoras de Sociologia das nossas entrevistadas. A professora B afirma que a sua experiência com as ocupações tornou sua escuta e atuação docente mais afetiva e próxima aos estudantes, incentivando sua articulação em projetos escolares com outros professores que atendam a proposições dos próprios estudantes. A professora $\mathbf{C}$, reflete que isso representa "uma consolidação da disciplina, que respondeu às inquietações deles". A demanda dos estudantes pelos "dois tempos mínimos", a nosso ver, assume um significado de "dever cumprido" pelas professoras. Num sentido de que se os estudantes estão exigindo mais tempos, é sinal de que a disciplina está cumprindo com as demandas que eles têm enquanto sujeitos. Deste modo, o discurso das ocupações afirma a necessidade e, ao mesmo tempo, reforça os argumentos em defesa da disciplina ${ }^{3}$.

Ainda em 2016, como resultado do acordo pelo fim da greve deste mesmo ano do SEPE/RJ, a SEEDUC/RJ se compromete a elaborar uma nova matriz curricular atendendo ao pleito de mínimo de dois tempos semanais por disciplina. A Resolução 5440/2016, da Secretaria de Estado de Educação (2016) oficializa o compromisso firmado, e ao começar no ano letivo de 2017, a Sociologia (e a Filosofia) passam a ter dois tempos semanais mínimos em todos os anos do Ensino Médio das escolas estaduais.

O discurso sobre os "dois tempos" surge com os professores no exercício da profissão, e circula pelas greves de professores, pelo movimento estudantil de ocupações, até tornar-se parte do acordo para encerramento da greve dos professores de 2016 feito pelo sindicato e a Secretaria Estadual de Educação. Este discurso, ainda, dá origem a um movimento social específico de professores de Sociologia e Filosofia o qual, conforme as entrevistas, contribui para que a professora A superasse o sentimento de isolamento.

Destarte, observamos as disputas por território, status e recursos nas narrativas das professoras entrevistadas. Procuramos demonstrar o entrelace entre esse processo e as histórias

\footnotetext{
${ }^{3}$ Muito embora possa existir relação entre o perfil dos estudantes e do discurso, o enfoque aqui é perceber que uma demanda específica da disciplina transcendeu o espaço da comunidade disciplinar; num outro sentido, um debate mobilizado principalmente entre professores e Secretarias de Educação apareceu em um movimento social protagonizado por jovens estudantes do Ensino Médio.
}

Olhar de Professor, Ponta Grossa, v. 24, p. I-22, e-14954.00I, 2021.

Disponível em https://revistas2.uepg.br/index.php/olhardeprofessor 
narradas pelas professoras, ao passo que procuramos capturar os discursos e demandas disciplinares relacionados ao contexto histórico. E assim percebemos nas narrativas a disciplina desde uma fase invisibilizada e restrita ao contexto da prática, até uma etapa onde aparece uma comunidade disciplinar mais abrangente como movimento social e como discurso, transcendendo e expandindo fronteiras, agregando novos atores e sujeitos, e assim fortalecendo os discursos em defesa da disciplina.

\section{Invenção de tradições}

Para Hobsbawn e Ranger (1997), o processo de invenção de tradições consiste em um conjunto de práticas inventadas cujo objetivo é inculcar valores e normas de comportamento, construindo um elo sempre que possível com o passado. As entrevistas trazem questões que sugerem a fragilidade das tradições da Sociologia escolar. A professora A expressa esta fragilidade ao comparar com as aulas Biologia, onde os alunos "levam aquele feijãozinho com algodãozinho" e já saberiam o que fazer. Estas disciplinas, como sugere a professora, já possuem práticas instituídas que representam um monólito inquebrantável. A professora $\mathbf{C}$ narra como a Sociologia em seu início de carreira parecia "mambembe". ${ }^{4}$

A intermitência da Sociologia no currículo escolar contribui para a ausência de solidez das tradições sociológicas na educação básica (SARANDY, 20I2). Pereira afirma que apesar do acúmulo dos quase 30 anos de disciplina obrigatória no Estado, ainda é difícil traçar uma identidade para a Sociologia (PEREIRA, 20I3). Com efeito, verificamos nas entrevistas estas mesmas problemáticas. A professora B nos lembra da indefinição sobre o papel do professor e da disciplina de Sociologia. E a professora C se questiona sobre se a disciplina terá "futuro bonito". A ausência de tradições inventadas desperta, neste sentido, dúvidas sobre a continuidade da disciplina. A insegurança aparece como um espectro que ronda as narrativas das professoras. É nesta zona nebulosa que parecem circular os discursos desenvolvidos pela comunidade disciplinar nas políticas, tanto do PNLD, quanto no Currículo Mínimo do Estado do Rio de Janeiro.

O PNLD aparece nas entrevistas e pode ser interpretado como um fator que contribui para o desenvolvimento de zonas de consenso acerca da prática dos docentes, através de um processo de avaliação com critérios de escolha centralizados, que se baseiam na pluralidade dos conceitos, respeito aos clássicos e na necessidade de uma abordagem específica para a Sociologia escolar. O próprio processo de escolha dos livros em 2015 e 2018 reforça a ideia de busca pela continuidade. Além da

\footnotetext{
4 O termo mambembe mencionado pela professora tem conotação de algo que é informal ou sem regulação ou controle.
} 
persistência dos critérios de escolha, dos seis livros escolhidos em 2015, cinco continuaram a fazer parte do universo de escolha das escolas em 2018.

Em sua narrativa, a professora A demonstra como o livro didático tornou-se uma ferramenta de defesa para o professor, na medida em que o conceito que ela trabalha em sala de aula se vincula ao que aparece escrito no livro. Ou seja, a professora utiliza o livro como um elemento que legitima um problema oriundo da prática. As entrevistas sugerem que professores mobilizam os discursos construídos por grupos disciplinares no momento elaboração da política para estabilizar suas próprias práticas, criando um vínculo tácito entre a aula e o livro didático. As três entrevistadas reforçam mesmo sem concordar exatamente a periodicidade - o aumento da participação dos estudantes nas aulas.

Já o Currículo Mínimo do Estado do Rio de Janeiro estabiliza "conteúdos mínimos" da disciplina. Ainda que nas narrativas as professoras rechacem a utilização literal do Currículo Mínimo, seu papel como "guia" merece destaque na carreira das três docentes. Por isso, tal como Goodson (2012) fez de modo geral, e como Souza (2017) entendeu ao analisar a construção do currículo mínimo de Sociologia do Estado do Rio de Janeiro, percebemos esta política como uma invenção de tradição.

Sendo assim, não surpreende que a professora A, que iniciou sua trajetória na década de 90 e, portanto, se socializou na profissão sem este guia curricular, conceba esta política como um elemento desorganizador da disciplina. A professora critica o documento ao lembrar que ele juntou conceitos de quadros teóricos completamente distintos. Porém, conforme nos lembra Hobsbawn e Ranger (1997) uma tradição inventada pode apresentar inconsistências quando a expomos a luz de argumento pragmáticos.

As entrevistas com as professoras evidenciam que o Currículo Mínimo acaba por atuar como um fio condutor que imprime coesão às suas práticas. Portanto, para além das contradições evidenciadas nas narrativas, o Currículo Mínimo aparece como uma tradição inventada, pois ele transmite continuamente valores, ideias e comportamentos. Mesmo que a narrativa da professora B indique outras contradições pedagógicas para o cumprimento dos conteúdos, ano após ano, as professoras lidam repetidamente com este guia curricular.

Então, apesar da diversidade de identidades de professores de Sociologia, relatados pela professora B, tanto o PNLD quanto o Currículo Mínimo agem criando zonas de consensos. Neste cenário, as tradições inventadas, para as professoras entrevistadas, produzem também uma linguagem compartilhada entre os distintos grupos da comunidade disciplinar, e, também, outros grupos externos.

A partir das narrativas, observamos que as políticas curriculares do PNLD e do Currículo Mínimo da SEEDUC/RJ aparecem como um território comum: habitado, explorado, e transformado 
pelas professoras. E este terreno comum instituído pelas tradições inventadas se torna terreno fértil para a criatividade dentro da própria prática docente.

Entendemos, portanto, que as narrativas investigadas indicam que estes territórios criaram possibilidades para a invenção de tradições no interior da própria escola. ${ }^{5}$ Nas entrevistas, destacamos como eventos escolares reforçam as tradições inventadas em cada escola, estabelecendo um vínculo contínuo com o passado, com a história da disciplina em cada ambiente escolar. É potente a narrativa da professora $\mathbf{C}$ sobre a Mostra de Cultura Negra, a qual surgiu a partir de inquietações dos próprios estudantes, como um movimento pequeno que hoje faz parte do calendário da escola. Ou sobre como a professora B se integrou num projeto em conjunto com outros professores para pensar a Arte Urbana e os espaços da cidade pelos quais os próprios alunos passavam em seus caminhos rotineiros. Do mesmo modo, é interessante que a professora A se questione sobre o porquê da Sociologia não se integrar às ciências naturais com um projeto para as Feiras de Ciências da escola.

Estas histórias sugerem que as iniciativas de invenção de tradições narradas pelas professoras privilegiam uma perspectiva utilitarista das tradições curriculares conforme conceitua Goodson (1997). Ainda que os discursos disciplinares oriundos dos documentos curriculares apareçam híbridos, na prática escolar, as professoras inventam tradições com caráter utilitário, ou seja, mais adequado à realidade dos estudantes.

Desta forma, percebemos como ocorre o processo de invenção de tradições nas narrativas das professoras. Ocorre o estabelecimento de zonas de consenso pela comunidade disciplinar, onde percebemos a produção de valores e signos mais estáveis e coesos para os docentes. E a partir daí, acabam por inventar e mobilizar tradições para a Sociologia no interior das escolas. Assim, estabelecem um vínculo contínuo com o passado, e produzem uma história para a sociologia dentro de cada ambiente escolar.

\section{Retórica em defesa da disciplina Sociologia}

A comunidade disciplinar, de acordo com Goodson (1997), produz retóricas que legitimam a sua defesa no currículo, angariando apoio constante de grupos externos à disciplina. Nas narrativas, as

\footnotetext{
${ }^{5}$ A partir das narrativas das professoras, a ideia de que a Sociologia não tem tradições como a Biologia, ou que no início da carreira era de forma mambembe, pretende deixar clara a percepção de ausência de um vínculo com o passado. Ao propor a ideia de zona de consenso queremos explicitar que existe um esforço de construção de um discurso que incute valores, ideias e signos os quais constroem um vínculo com o passado. Desta construção também entendemos que podemos inferir uma gama de ações individualizadas dos professores. No entanto, preferimos deixar esta relação implícita para dar enfoque no processo de invenção de tradições, pois a grande variedade de tradições individualmente mobilizadas poderia estar relacionada também ao perfil heterogêneo dos professores de Sociologia já verificado em pesquisas, como por exemplo em Polessa et al (2012).
}

Olhar de Professor, Ponta Grossa, v. 24, p. I-22, e-I4954.00I, 2021.

Disponível em https://revistas2.uepg.br/index.php/olhardeprofessor 
professoras admitem a impossibilidade de ser professor de Sociologia e de não ter uma atuação política favorável à presença da disciplina na Educação Básica. Sua condição instável no currículo, mobiliza as professoras para exercerem e ocuparem espaços em favor da Sociologia. Estes espaços aparecem numa conversa rotineira com seus pares, como relatou a professora $\mathbf{A}$, ou em espaços de movimento de greve ou de lutas específicas, tal qual a do Fórum dos professores de Filosofia e Sociologia.

No quadro abaixo apresentamos uma síntese os principais argumentos em defesa da disciplina relatados pelas professoras:

Quadro 2 - Argumento das entrevistadas em defesa da disciplina Sociologia

\begin{tabular}{|c|l|}
\hline Professora & Argumento de defesa \\
\hline A & Desconstrução do senso comum e formação para a Cidadania. \\
\hline B & Desnaturalização do mundo e desconstrução do senso comum. \\
\hline C & Desnaturalização e Estranhamento para a formação do estudante. \\
\hline
\end{tabular}

Fonte: produzido pelos autores, 2019.

Observamos nas entrevistas os conceitos de estranhamento e naturalização sendo mobilizados para uma perspectiva mais utilitarista do currículo. Tais conceitos fundamentam as retóricas que as professoras constroem com um ponto de vista sempre aproximado a alguma realidade vivenciada pelos estudantes.

Mesmo a desconstrução do senso comum, a qual poderia estar vinculada a uma concepção de Sociologia mais acadêmica similar a dos formuladores dos primeiros manuais ( $\mathrm{MEUCCl}, 2000$ ), assume um tom predominantemente utilitário ao analisarmos mais a fundo as práticas da professora $\mathbf{A}$. Durante sua entrevista, a professora relata a importância dos sábados letivos onde, de forma interdisciplinar, havia atividades com a participação de representantes de movimentos sociais do entorno da escola. Neste momento, a professora afirma que percebe o sentido da Sociologia na escola, na desnaturalização do senso comum presente na realidade dos próprios estudantes, ou nas palavras da professora, as atividades interdisciplinares com movimentos sociais cuja atuação é próxima à escola, "era um momento em que as pessoas viam a escola mais próxima a elas".

Deste modo, o exame das narrativas sugere que os argumentos em defesa da sociologia das professoras entrevistadas indicam uma aproximação com as tradições utilitaristas do currículo destacadas por Goodson (200I). Neste mesmo sentido, observamos que as retóricas das docentes contêm majoritariamente elementos ideais e morais. Goodson (1997) destaca que as retóricas mais bem-sucedidas são aquelas que fundem elementos morais, ideias e materiais. $O$ estranhar e desnaturalizar o mundo, a formação para a cidadania e a desconstrução do senso comum articulam 
concepções morais e ideias do papel da disciplina, de professor e, num sentido geral, da escola. No entanto, não conseguimos perceber perspectivas materiais na defesa da disciplina pelas professoras.

Este resultado da pesquisa corrobora com as hipóteses postuladas de Sarandy (2012) acerca do desenvolvimento histórico das ciências sociais no Brasil. Para o autor, as ciências sociais se desenvolveram como uma disciplina insulada (SARANDY, 20I2), ou seja, como uma "ilha". O autor afirma que a expansão e institucionalização dos programas de pós-graduação em ciências sociais no Brasil ocorreram durante o Regime Militar, o qual afastou estes pesquisadores dos grupos decisórios no país. É neste sentido que compreendemos que a ausência de elementos materiais nas retóricas em defesa da disciplina nas narrativas obtidas nas entrevistas desta pesquisa pode estar associada à condição insular de desenvolvimento das ciências sociais no país.

\section{Conclusões}

No decorrer dessa pesquisa, tivemos como objetivo analisar a relação dos professores com a construção social do currículo. Portanto, uma premissa deste trabalho entendia que não era possível "ser professor e só dar aula", como nos dissera a professora C. Sem a pretensão de encerrar o debate, nosso foco era ajustar nosso olhar para compreender como indivíduos ou grupos disciplinares mobilizam as disputas curriculares a partir de sua própria trajetória de vida.

Com efeito, o desenvolvimento deste trabalho nos sugere a potência de metodologias que articulem histórias de vida profissional e construção social do currículo. Existe uma infinidade de narrativas a serem descobertas, de sujeitos (professores) vivendo a sua própria história. Um enfoque mais etnográfico, por exemplo, pode revelar, no detalhe, o processo de construção e legitimação de uma disciplina dentro do espaço escolar. Estes aparecem como caminhos possíveis e potentes para a contribuição de um entendimento cumulativo dos diversos contextos que envolvem a permanência, defesa e promoção de uma disciplina escolar.

E neste sentido, a nossa investigação da trajetória profissional das professoras sugere que o processo de estabilização da disciplina Sociologia no estado do Rio de Janeiro passou por fases: seja uma primeira fase de um esquecimento estável, de 1998 a 2008, onde a disciplina existe no currículo, mas com pouco espaço para o fortalecimento e o estabelecimento de redes dentro da comunidade disciplinar. No entanto, ela está acomodada ao currículo a partir da própria ausência de disputas por território, recursos e status.

Na segunda fase, a partir da promulgação de 2008, a Sociologia passa por uma transição ambígua; por um lado, com as condições de trabalho precarizadas no Estado do Rio de Janeiro; e por 
outro com um fortalecimento da comunidade disciplinar. As narrativas sugerem esta fase como uma "fase árdua", onde após mudanças na matriz curricular, a Sociologia aparece em todos os anos do Ensino Médio com um tempo de 50 (cinquenta) minutos de aula. Apesar deste espaço mínimo de carga horária e de piora para realização de um trabalho docente, é nesta fase que observamos uma intensificação das disputas por recursos, territórios e status. Assim, percebemos um fortalecimento da comunidade disciplinar, com recrutamento de novos professores, e das redes mais amplas, como em outras esferas das políticas curriculares. Em nível nacional a Sociologia apareceu no PNLD e nas Orientações Curriculares Nacionais para o Ensino Médio (OCNEM); e no âmbito estadual, observamos o aparecimento no Currículo Mínimo, na mobilização de demandas nos movimentos de greve da categoria de professores do Estado, e nas reivindicações das ocupações estudantis.

Desta forma, nesta fase ambígua, interpretamos que estes movimentos favoreceram o processo fortalecimento da comunidade disciplinar. Assim percebemos as conquistas de território, status e recursos, com a aceitação da demanda por uma carga horária mínima para a disciplina. E também, o processo de criação de tradições e retóricas no exercício da docência com as Mostras de Cultura, Projetos Integradores, Debates com Movimentos Sociais, promovidos pelas professoras que acabam ocupando um lugar tradicional nas escolas.

Não obstante, de acordo com as narrativas, percebemos ainda a disciplina numa terceira fase. Nesta etapa a comunidade disciplinar aparece, com efeito, mais consolidada, na forma de associações e espaços tradicionalmente ocupados pelos professores de Sociologia, e com suas retóricas se associando e subsidiando a prática das professoras entrevistadas. Isso não quer dizer que a Sociologia adquiriu uma condição estável, de "monólito mitificado" (GOODSON, 1997). A presença ou ausência de uma disciplina no currículo é fruto de uma construção social (GOODSON, 1997, 2012), que envolve atores em uma disputa por território, recursos e status; numa construção de retóricas em defesa da disciplina; e em invenção de tradições. A disciplina bem-sucedida é aquela em que a retórica em sua defesa e suas tradições, se confundem com a defesa e história da própria da escola.

Sendo assim, esse processo mostra-se dinâmico e sempre em movimento. Estas categorias aparecem sempre em confronto com a realidade, com o tempo presente; ou com a recuperação de um passado, com o reforço de uma tradição. Por isso, novos trabalhos com esta temática podem surpreender outras retóricas, outras tradições que fortaleçam a comunidade disciplinar da Sociologia.

Este processo contínuo de defesa da disciplina consiste no elemento chave que a nossa pesquisa procurou surpreender na trajetória de vida de três professoras. Destarte, perseguimos uma interpretação que superasse a dicotomia entre estrutura e agência e valorizasse a criatividade e luta dos docentes na defesa neste processo. Desta forma, de fato, não seria possível "ser professor e só 
dar aula". Os professores aparecem diretamente como sujeitos de suas histórias e da própria Sociologia escolar.

\section{Referências}

BALL, S. What is policy? Texts, trajectories and toolboxes. In: BALL, STEPHEN (Org.). Discourse: studies in the cultural politics of education. Londres: King's College, 1993.

BALL, S., MAGUIRE, $M$ e BRAUN, A. Como as escolas fazem política: atuação em escolas secundárias. Ponta Grossa: Editora EUPG. 2016.

BRASIL. Lei n $\mathbf{0} 6.888$ de 10 de dezembro 1980 Dispõe sobre o exercício da profissão de Sociólogo e dá outras providências. Brasília: [s.n.]. 1980

BRASIL. Lei $\mathbf{n}^{\circ} \mathbf{9} \mathbf{9 . 3 9 4}$ de $\mathbf{2 0}$ de dezembro de 1996. Estabelece as diretrizes e bases da educação nacional. Brasília: [s.n], 1996.

BRASIL. Lei $\mathrm{n}^{\circ}$. 13.415 de 16 de fevereiro de 2017 . Altera as Leis $n^{\circ} 9.394$, de 20 de dezembro de 1996, que estabelece as diretrizes e bases da educação nacional, e II.494, de 20 de junho 2007, que regulamenta o Fundo de Manutenção e Desenvolvimento da Educação Básica e de Valorização dos Profissionais da Educação, a Consolidação das Leis do Trabalho - CLT, aprovada pelo Decreto-Lei ${ }^{\circ}$ 5.452, de $1^{\circ}$ de maio de 1943, e o Decreto-Lei $n^{\circ} 236$, de 28 de fevereiro de 1967; revoga a Lei $n^{\circ}$ II.16I, de 5 de agosto de 2005; e institui a Política de Fomento à Implementação de Escolas de Ensino Médio em Tempo Integral. Brasília: [s. n.], 2017.

BRASIL. Lei $\mathbf{n}^{\circ} \mathbf{7} \mathbf{7 . 0 4 4}$ de 18 de outubro de 1982. Altera dispositivos da Lei $n^{\circ}$ 5.692, de II de agosto de 197I, referentes a profissionalização do ensino de $2^{\circ}$ grau. Brasília. 1982.

BRASIL. Lei $\mathbf{N}^{\circ}$ I I.684, de 2 de junho de 2008.Altera o art. 36 da Lei no 9.394, de 20 de dezembro de 1996, que estabelece as diretrizes e bases da educação nacional, para incluir a Filosofia e a Sociologia como disciplinas obrigatórias nos currículos do ensino médio. Brasília. 2008.

BRASIL. Parecer n³8/2006 CNE/CEB, de 7 de julho de 2006. Inclusão obrigatória das disciplinas de Filosofia e Sociologia no currículo do Ensino Médio. Brasília. 2006.

BRASIL. Resolução nI/2009 CNE/CEB, de 18 de maio de 2009. Inclusão obrigatória das disciplinas de Filosofia e Sociologia no currículo do Ensino Médio. Brasília. 2009.

CONTERATO, S. A saga da Sociologia no Ensino Médio. Perspectiva Sociológica: A Revista de Professores de Sociologia, n. 3, 2009.

COSTA, H. H. C.; LOPES, A. C. A comunidade disciplinar em Goodson: impasses em um registro pósestrutural. Revista Brasileira de Educação, v. 21, n. 67, p. 1009-1032, 2016. Disponível em: $<$ https://doi.org/|0.1590/SI4|3-2478201621675|>.

DUARTE, R. Entrevistas em pesquisas qualitativas. Educar, n² 24. Curitiba - PR: jul./dez, 2004. p. 2I3-225.

Olhar de Professor, Ponta Grossa, v. 24, p. I-22, e-I4954.00I, 202 I.

Disponível em https://revistas2.uepg.br/index.php/olhardeprofessor 
GILL, S. e GOODSON, I. Métodos de história de vida e narrativa. In: SOMECK, B. e LEWIN, C. (Orgs.) Teorias e métodos de pesquisa social. Petrópolis: Vozes, 2015: 215-224.

GOODSON, I. A construção social do currículo. Lisboa: Educa, 1997.

GOODSON, I. O currículo em mudança: estudos na construção social do currículo. Porto: Porto Editora, 200I.

GOODSON, I. (Org.). Currículo: Teoria e história. I2a ed. Petrópolis: Editora Vozes, 2012.

HANDFAS, A.; MAIÇARA, J. P. O estado da arte da produção científica sobre o Ensino de Sociologia. In: HANDFAS, A.; MAIÇARA, J. P.; FRAGA, A. B. (Org.) Conhecimento Escolar e Ensino de Sociologia. Rio de Janeiro: 7 letras, 20 I5. p. 25-45.

HOBSBAWN, E.; RANGER, T. A invenção das tradições. Rio de Janeiro: Paz e Terra, 1997.

LOPES, A. C. Política de currículo: recontextualização e hibridismo. Currículo sem Fronteiras, v. 5, n. 2, p. 50-64, 2005.

MAIÇARA, J. P.; MONTEZ, G.; GESTEIRA, B. Currículos em mudança: a prática do ensino de Sociologia no Rio de Janeiro. In: HANDFAS, A.; MAIÇARA, J. P.; FRAGA, A. B. (Org.) Conhecimento Escolar e Ensino de Sociologia. Rio de Janeiro: 7 letras, 20I5. p. I0I-II4.

MEUCCI, S. A Institucionalização da sociologia no Brasil: os primeiros manuais e cursos. Campinas, 2000. 158 f. Dissertação (Mestrado em Sociologia). Instituto de Filosofia e Ciências Humanas, Universidade Estadual de Campinas, Campinas 2000.

MORAES, A. Ensino de Sociologia: periodização e campanha pela obrigatoriedade. Cadernos Cedes, v. 3I, n. 85, p. 359-382, 20I I. Disponível em: < http://dx.doi.org/I0.1590/S0I0I-326220I I000300004 $>$.

MOTA, K. C. C. D. S. Os lugares da sociologia na formação de estudantes do ensino médio: as perspectivas de professores. Revista Brasileira de Educação, n. 29, p. 88-107, 2005. Disponível em: < http://dx.doi.org// 0.I590/SI4I3-24782005000200008>.

OLIVEIRA, A. Revisitando a história do ensino de Sociologia na Educação Básica. Acta Scientiarum. Education, v. 35, n. 2, p. 179-189, 2013. Disponível em: <http:// dx.doi.org/ 10.4025/actascieduc.v35i2.20222 >.

OLIVEIRA, A. e CIGALES, M. P. O ensino de Sociologia no Brasil: um balanço dos avanços galgados entre 2008 e 2017. Revista Temas em Educação, João Pessoa, Brasil, v. 28, n.2, p.42-58, maio/ago 2019.

PEREIRA, M. M. T. A construção social da identidade da sociologia como disciplina escolar : que sociologia é essa? Rio de Janeiro. 20I3. 180 f. Dissertação (Mestrado em Ciências Sociais). Instituto de Filosofia e Ciências Humanas, Universidade do Estado do Rio de Janeiro.

POLESSA, J.; GESTEIRA, B.; MONTEZ, G. Perfil do professor de Sociologia da Metropolitana VI da Rede Pública Estadual do Rio de Janeiro. In: FIGUEIREDO, A. V. DE; OLIVEIRA, L. F. DE; PINTO, N. M. (Org.). Sociologia na Sala de aula: reflexões e experiências docentes no Rio de Janeiro. Rio de Janeiro: Imperial Novo Milênio, 2012.

Olhar de Professor, Ponta Grossa, v. 24, p. I-22, e-I4954.00I, 202 I.

Disponível em https://revistas2.uepg.br/index.php/olhardeprofessor 
QUEIROZ, D. F. S.; BORTOLON, P. C.; ROCHA, R. C. M. As Ocupações Estudantis e a Reinvenção do Espaço Escolar Facilitadas pelas Tecnologias Interativas. Arquivos Analíticos de Políticas Educativas, v. 25, n. 104, 20I7.eiro, Rio de Janeiro, 2013.

SECRETARIA DE ESTADO DE EDUCAÇÃO, Resolução $\mathbf{n}^{\circ}$. 4359, de 19 de outubro de 2009. Fixa diretrizes para implantação das matrizes curriculares para educação básica nas unidades escolares da rede pública e dá outras providências. Rio de Janeiro, 2009.

SECRETARIA DE ESTADO DE EDUCAÇÃO, Resolução $\mathbf{n}^{\circ}$. 5440, de 10 de maio de 2016. Dispõe sobre o Anexo II da Resolução da SEEDUC N ${ }^{\circ} 5330 / 2015$, e dá outras providências. Rio de Janeiro, 2016.

SANTOS, M. B. A sociologia no contexto das reformas do ensino médio. In: CARVALHO, L. M. G. A. (Org.). Sociologia e ensino em debate: experiências de Sociologia no Ensino Médio. ljuí: Ed. Unijuí, 2004. p. $|3|-\mid 80$.

SARANDY, F. M. S. Ensino de Sociologia: insulamento e invisibilidade de uma disciplina. In: FIGUEIREDO, A. V.; OLIVEIRA, L. F.; PINTO, N. M. (Org.) Sociologia na Sala de aula: reflexões e experiências docentes no Rio de Janeiro. Rio de Janeiro: Imperial Novo Milênio, 20I2. p. 34-6I.

SOUZA, S. M. A. N. A defesa da disciplina sociologia nas políticas para o Ensino Médio de 1996 a 2007. Rio de Janeiro, 2008. 87 f. Dissertação (Mestrado em Educação). Faculdade de Educação, Universidade Estadual do Rio de Janeiro, Rio de Janeiro, 2008.

SOUZA, A. C. A Sociologia escolar: imbricações e recontextualizações curriculares para a disciplina. Araraquara, 2017. 363 f. Tese (Doutorado em Ciências Sociais). Faculdade de Ciências e Letras, Universidade Estadual Paulista, Araraquara, 2017.

SOUZA, A. M. E; HANDFAS, A.; FRANÇA, T. M. A trajetória de institucionalização da Sociologia na Educação Básica no Rio de Janeiro. In: FIGUEIREDO, A. V.; OLIVEIRA, L. F.; PINTO, N. M. (Org.) Sociologia na Sala de aula: reflexões e experiências docentes no Rio de Janeiro. Rio de Janeiro: Imperial Novo Milênio, 2012.

Recebido em: 03 de março de 2020.

Versão corrigida recebida em: 20 de outubro de 2020.

Aceito em: II de novembro de 2020.

Publicado on line em: 05 de março de 2020.

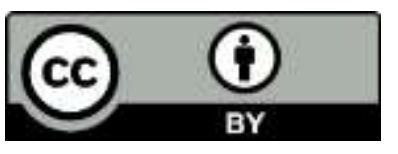

Olhar de Professor, Ponta Grossa, v. 24, p. I-22, e-I4954.00I, 202 I.

Disponível em https://revistas2.uepg.br/index.php/olhardeprofessor 